\title{
Die ambivalente aard van skoonheid en begeerte in die Ou Testament
}

\author{
Lisel Kruger \& J.P.J. Olivier \\ Departement Ou en Nuwe Testament \\ Universiteit van Stellenbosch \\ STELLENBOSCH \\ E-pos: jpo@akad.sun.ac.za
}

\begin{abstract}
The ambivalent character of beauty and desire in the Old Testament

Psalm $+5: 12$ and Proverbs 5:25 are identified as the only wo places in the Old Testament where the Hebrew word $7 \nabla_{7}^{7}$ for beauty is the subject of the wo verbs 7) desire. An exegetical comparison beween the n'o lext verses show's an atrinde towards the desire for beauty which proves to be ethical ambivalent. According to this exegesis the social religious context determines the positive or negative experience or consequences of beauty and desire This ambivalence introduces another perspective on the Tenth Commandment, as this view cancels any rigid interpretation of coveting: because the integrity of the covenant relationship between God and his people sanctions the acceptability or not of the use of beauty, or the desire of it.
\end{abstract}

\section{Inleiding}

Die aard van "skoonheid" en "begeerte" in die Ou Testament is die fokuspunt van hierdie artikel aangesien die artikel gemotiveer is deur ' $n$ belangstelling in die estetiese aspekte in die Ou Testament. Alhoewel hierdie artikel slegs 'n klein aspek van die Ou-Testamentiese verstaan van skoonheid aanraak, wil dit tog ' $n$ bydrae maak tot die verstaan van die dinamika van die estetiese in die Ou Testament. Saam met die nadenke oor skoonheid het die vraag na die teologiese belang en oordeel van begeerte (na aanleiding van verskeie interpretasies van die tiende gebod) verdere impetus aan die ondersoek verskaf. Die artikel het ten doel om deur die identifisering van die aard van skoonheid en begeerte in die Ou Testament moontlik nuwe perspektiewe te verskaf vir die verstaan van die tiende gebod in die Dekaloog.

Die legitimiteit van hierdie hipotese is afhanklik van sekere metodologiese besluite wat die grense van hierdie artikel sal bepaal. Die leemtes in die artikel gaan gepaard met hierdie keuses. 'n Vergelykende metodologie sal gevolg word, met inagneming van ander legitieme benaderings. Binne die verskeie fasette van die estetiese in die Ou Testament word die "mooi mens" uitgesonder 
vir bestudering. Met inagneming van die gebod op begeerte, is die voorkoms van die twee werkwoorde vir begeerte (Deut. 5:21) buite die Dekaloog nagegaan. Slegs twee gedeeltes is geïdentifiseer waar die "mooi mens" (meer spesifiek die mooi vrou) die objek van begeerte is - te wete Psalm 45:11-12 en Spreuke 6:25.1 Aandag sal eerstens kortliks geskenk word aan die aard en voorkoms van die "mooi mens" in die Ou Testament asook die verskillende verstaansmodi van begeerte. Daarna sal Psalm 45 en Spreuke 6 as konteks vir hierdie begrippe bestudeer word, met die slotvraag of hierdie bevindinge ' $n$ bydrae verskaf tot ' $n$ verstaan van die tiende gebod.

\section{Die aard van menslike skoonheid in die $\mathrm{Ou}$ Testament}

Augustin (1983:23) erken die omvangrykheid van estetiese konsepte in die Ou Testament. Behalwe die rol wat menslike skoonheid in die verskillende OuTestamentiese genres speel, manifesteer dit ook in ander sfere, byvoorbeeld skoonheid in die kultus, musiek, poësie, argitektuur, natuur en wysheid. ${ }^{2}$ In die geskiedenis van die Skrifmterpretasie is die kwessie van menslike skoonheid vanselfsprekend in verband gebring met die lofprysing van die liggaamlike skoonheid van die man en die vrou in die boek Hooglied. Die konsep van die mooi mens lê egter in die Ou Testament wyer as dit en daar moet ook in hierdie ruimtes inbeweeg word om die rol of aard van skoonheid in die verskillende genres en kontekste te verstaan.

\subsection{Terminologie}

Enkele Hebreeuse woorde is geïdentifiseer waaraan die betekenismoontlikheid/ vertalingsekwivalent mooi/goed verbind kan word. In die Skeppingsverhale en -narratiewe is $ב 10$ 'n algemene aanduiding van die goeie of selfs die mooi mens (bv. Gen. 2:6; Eks. 2:2; 1 Kon. 1:6). Ook $7 \Pi$ kan, behalwe die basiese betekenis van genade en guns, dui op menslike sjarme en styl (Reines, 1975:100).

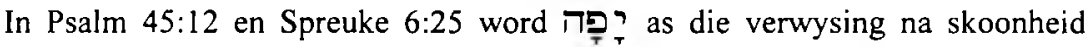
aangetref. In verskeie Ou-Testamentiese gedeeltes word hierdie wortel veral

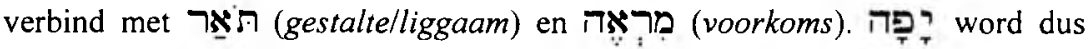
verbind met die uiterlike, liggaamlike skoonheid. Sowel mans (Dawid, Absalom, Josef) as vroue word in die Ou Testament as "mooi" geteken en

Psalm 45:1 1-12: "Hoor dogter, kyk en luister. Vergeet jou volk en jou huis en jou vader, want

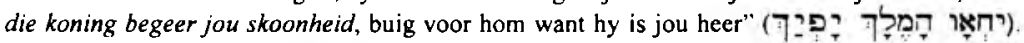
Spreuke 6:25: "Moenie haar skoonheid in jou hart begeer nie, moenie dat sy jou vang met haar

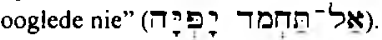

2 Augustin (1983:14-23) verskaf 'n volledige oorsig oor die literatuur (vanaf 1753) wat in 'n mindere of meerdere mate aan die estetiese in die Ou Testament aandag gee. 
hierdie skoonheid wek begeerte by die teenoorgestelde geslag (Gen. 29:18; 2 Sam. 13:1; Spr. 6:25; Ps. 45:12). Dwarsdeur die geskiedenis het die mooi mens (man en vrou) ' $n$ groot rol gespeel in die keuses en optredes van figure uit die Ou-Testamentiese literatuur en geskiedenis.

\subsection{Die aard van skoonheid}

Westermann (1977:483) onderskei tussen skoonheid as ontologiese gegewe (Seiendes) en skoonheid as gebeure (Geschehendem). Menslike skoonheid in die Ou Testament identifiseer hy met "skoonheid as gebeure". Skoonheid is in terme hiervan 'n dinamiese erkenning waar man en vrou ontmoet, eerder as dic blote waarneming van 'n gegewe objek. In verskeie Ou-Testamentiese narratiewe word skoonheid dan ook juis as 'n konfliksmotief geïdentifiseer. Die ontmoeting van geslagte illustreer vir Westermann (1977:483) skoonheid as gebeure wat die potensiaal tot konflik het: "Die Schönheit des Menschen wird in der Begegnung entdeckt, wird in der Begegnung erfahren".

Die "skoonheid as gebeure" behoort tot die menswees van elke persoon. Menslike skoonheid word nou verbind met die skepsels en skeppingswerke van God en staan sodoende in die teken van God se seën (vgl. ook Wolff, 1974:6974 oor "Beauty").

'n Ander belangrike perspektief op skoonheid is die etiese perspeltief Skoonheid word as eties ambivalent geteken en ervaar deurdat die gevolge van begeerte na skoonheid positief of negatief kan wees. Hierdie ambivalente aard van die skone is sedert die skepping reeds aanwesig (vergelyk die begeerte na die boom van kennis). Augustin (1983:55) meen dat as bekoorlikheid daartoe lei dat die mens grense oorsteek, die strewe na skoonheid 'n oortreding word: "Erst wenn der Reiz des Verboten das Begehren steigert und die dem Menschen gesetze Grense überschreitert wird das Streben nach dem Schönen zum Frevel".

Skoonheid word dus in die Ou Testament ervaar as teken van God se seën. Die dinamiese (skoonheid as gebeure) en eties ambivalente aard van skoonlıeid moet egter erken word - 'n erkenning wat lei tot die nadenke oor die teologiese belang van die ingewikkelde verband tussen skoonheid en begeerte, en begeerte en "sonde".

\section{Die aard van begeerte in die Ou Testament}

Die korrekte verstaan van hierdie menslike emosie/wens in elke gegewe situasie is moeilik. Dit blyk duidelik uit die verskillende nuanses wat in die onderskeie kontekste in "begeerte" erken word.

Die erkenning van die sinnnieme/parallelle betekenis rus op die volgende argumente, naamlik die gebruik van die twee woorde in 'n parallelisme in 
Genesis 3:6. In Spreuke 6:25 en Psalm 68:17 verskyn die twee woorde in dieselfde samehang as by Psalm 45:12 en 132:13.

'n Kernprobleem, veral by die Dekaloog se verbod op begeerte, is die vraag of die Hebreeuse werkwoorde ארוד לָ bloot dui op 'n houding/gevoel (mental attitude) en of die werkwoorde daadwerklike optrede insluit. Die interpretasiegeskiedenis van die tiende gebod het aan begeerte 'n hoofsaaklik negatiewe konnotasie verskaf; daarom sal 'n statiese verstaan van begeerte, veral in verband met skoonheid, in heroorweging geneem word.

\subsection{Terminologie}

Die wortels ארה en ward as betekenisverwant erken. (Vergelyk Mayer (1973) vir 'n volledige bespreking van die voorkoms en betekenis van ארח in die Ou Testament; vgl. Wallis (1973) vir חמד.) 'n Onderskeid in vertalingsnuanses is afhanklik van die literêre konteks van die woorde. 'n Subtiele onderskeidingsnuanse kan egter gemaak word: חמד het meestal te make met sigbare persone of onderwerpe en selde met die abstrakte, terwyl אור in verband gebring word met die menslike verbeelding. In Engels kan hierdie אוה enderskeid duideliker vertaal word deur met covet. Mickler (1983:46) interpreteer die gebruik van hierdie woorde soos volg: "In Hebrew these words combine an understanding of spontaneous attraction with the actual will to possess the object desired".

Die ondersoek na die kontekste waarbinne die woorde gebruik word, maak dit duidelik dat begeerte sowel positief as negatief getipeer word. Skoonheid het, soos begeerte in die Ou Testament, ook 'n eties ambivalente karakter. 'n Presiese verstaan van hierdie woorde is onmoontlik los van die konteks waarbinne dit gebruik word en daarom is 'n dinamiese verstaan van begeerte in die Ou Testament nie haalbaar nie.

Die ambivalente aard van skoonheid en begeerte in die Ou Testament sal nou verder aan die hand van die twee geïdentifiseerde Skrifgedeeltes (Psalm 45:12 en Spreuke 6:25) bestudeer word.

\section{Skoonheid en begeerte in Psalm 45}

Psalm 45 is 'n Koragitiese Psalm wat as 'n koningspsalm geïdentifiseer word. Die koningspsalms moet verstaan word te midde van hulle spesifieke Sitz im Leben, naamlik die koninklike hofhouding (Von Rad, 1961:317)3. Kraus

3 Die moontlike Messiaanse verstaan van die koning word deur baie kommentatore gepropageer om legitimiteit aan die koningspsalms vir homiletiese doeleindes vir vandag te verskaf. 
(1986:15) interpreteer die Psalms as produkte van Israel se kultiese gemeenskap met Jahwe. Die noue band tussen die priesterlike en wysheidskole in Jerusalem onderstreep ook die invloed van die Wysheidstradisies op die Psalms (Kraus, 1986:15). Die didaktiese gedeeltes reflekteer dus die aanvaarbare optredes binne die Israelitiese samelewing.

Psalm 45 dui op die poëtiese viering van 'n huweliksfees, wat deel uitgemaak het van die uitgebreide koninklike kultus. ${ }^{4}$ Die heerlikheid van die koning as geseënde van God staan sentraal in dié Psalm. Ook die huwelik is in verband gebring met die kultus wat alle aspekte van die lewe omvat. Binne die Dawidiese dinastie word die koning as ontvanger van God se seën geëer. Hierdie seën word gereflekteer in die skoonheid en prag wat in die loflied aan hom toegewy word. Die koning verteenwoordig in sy voorkoms die God aan wie hy toegewy is. Psalm 45 word pre-eksilies gedateer en binne die hofkonteks van die monargie geplaas, alhoewel die presiese datering egter nie afgelei kan word nie. (Patterson (1985:33) gee 'n oorsig oor moontlike historiese situasies wat tot die skryf van hierdie spesifieke Psalm kon aanleiding gee.)

Psalm 45 prys die koning, maar die skoonheid van sy bruid is egter die fokuspunt van hierdie artikel. Psalm 45:11-12 is 'n vermaning tot onderdanigheid aan die bruid van die koning. Hierdie vermaning word uitgespiraal deur die psalmskrywer, moontlik 'n belangrike persoon aan die hof. Augustin (1983:157) identifiseer drie elemente in die vermaningsrede: Die vrou moet (a) haar volk/vaderhuis vergeet, want sy is nou deel van die familie/dinastie van die koning, (b) haar skoonheid behoort nou aan die koning en (c) sy moet haar voor hom neerbuig en eerbied aan hom betoon. Dit is dus ' $n$ oproep tot onderdanigheid wat die gevolg is van die koning se begeerte na die skoonheid van die

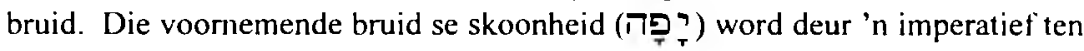
dienste gestel aan die begeerte (אוה) van die koning. Augustin (1983:160) identifiseer vers 12 as die enigste plek in die Ou Testament waar 'n begrip uit die woordveld van die menslike skoonheid (יפיר) die objek van die werkwoord (דר) is. Hierdie didaktiese of vermaningselement kan geinterpreteer word as 'n element van huweliks- of selfs monargale etiek.

Die oproep tot onderdanigheid is die gevolg van die koning se begeerte na die skoonheid van die bruid. Die sosio-religieuse opset van Israel legitimeer hierdie begeerte. In die Israelitiese samelewingsorde was die vrou onder die gesag van haar man en as voornemende bruid was sy verplig om haar lojaliteit te verruil. Die instelling van die huwelik asook die sosiale posisie van die koning legitimeer in hierdie konteks die begeerte van skoonheid.

4 Mayes (1994:346) bespreek ander moontlike kontekste vir die Psalm. 


\section{Skoonheid en begeerte in Spreuke 6}

Spreuke 1-9 word veral gekenmerk deur die wel en wee van twee vroue,

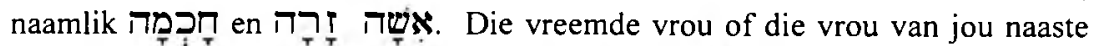
word ervaar of verstaan as simbool van of 'n nie-Israelitiese kultiese godin wat Israel se trou aan God bedreig of die vrou van vlees en bloed wat haar as die verleidster en egbreukster voordoen. 5

Albei hierdie verstaansmodi is gevestig in die wysheidsleraar se propagering en bevestiging van die verbondsamelewing. Die leermeester waarsku teen elke persoon/godsdiens wat dreig om hierdie fondamente te ondergrawe. Camp (1985:27) erken hierdie vreemde vrou dan ook as 'n sterk genuanseerde figuur in die Bybelse literatuur - 'n figuur wat gevorm is uit die meervoudige ervaring van Israel met vroue en die verhouding tussen die twee geslagte. Die uitbeelding is dus nie los van die ervaringswêreld van Israel nie. Camp identifiseer ook die tweeledige klem in Spreuke 1-9, te wete egbreuk en trou: “... inevitable overtones of the covenant relationship between Yahweh and Israel represented by the marriage bond - as though condemnation of adultery at the same time suggested the proclamation of fidelity to the covenant-God". Die afwysing van egbreuk is dus 'n oproep tot morele trou aan Jahwe.

Die vreemde vrou is dus 'n tipe van enige vrou wat deur haar skoonheid die konvensies van die gemeenskap minag. Spreuke 6:25 is die enigste plek waar

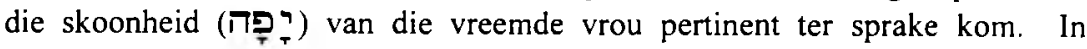
Spreuke 6 word ' $n$ vrou van 'n ander gemeenskap of stam wat egter in dieselfde omgewing bly (moontlik die vrou van 'n handelaar), aangetref. Op grond van haar skoonheid en optrede is sy baie opvallend vir die jong getroude en ongetroude mans. Haar skoonheid kan as konfliksmotief dien wat kan lei tot gebeure wat negatiewe gevolge vir die huis en die voortbestaan van die jong man kan inhou, indien hy in sy begeerte die grense van bepaalde gemeenskapsnorme oorsteek.

Die vermanings in Spreuke is ingebed in die wysheidstradisies van die ouerhuis en priesters en onderstreep die belang van die wet. In die vermaning teen die begeerte na die skoonheid van die vrou word die negatief-etiese aard van skoonheid en begeerte in Spreuke duidelik. In die wysheidstradisie kan begeerte aanleiding gee tot egbreuk, en egbreuk is binne die verbond 'n sonde teen God. Die getroude vrou oortree grense met haar skoonheid ter wille van die behoud van haar eie groep. Westermann (1977:479-497) se beskrywing van skoonheid as gebeure kan in die dinamiese aantrekkingskrag van die vrou se

5 Die vraagstuk na die aard van die vreemde vrou hang ook saam met die bespreking van die eenheid van Spreuke 6. McKane (1970:328) verskaf detail oor die bestaande hipoteses. 
optrede en die man se begeerte herken word. Die skoonheid bedreig hier die kern van die Israelitiese etos en wêreldbeeld, naamlik die gesin.

\section{Vergelyking tussen Spreuke 6 en Psalm 45}

Die ambivalente aard van die begeerte na skoonheid, veral op etiese gebied, is duidelik na die bestudering van Psalm 45:12 en Spreuke 6:25.

\subsection{Terminologie}

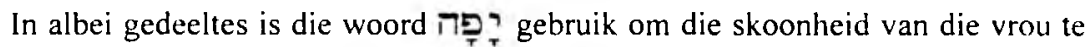
tipeer. In Spreuke 6:25 dui אוד in Psalm 45 die koning se houding definieer. In Spreuke 6 het 'n negatiewe teologies-etiese betekenis waar daar teen begeerte gewaarsku word. In Psalm 45 behels die vermaning juis die aanvaarding van begeerte en het begeerte dus 'n eties-neutrale of selfs positiewe aard.

\subsection{Vermaning}

Wysheid is onderliggend aan die vermanings in albei gedeeltes. In Psalm 45 word die toekomstige koningin deur die psalmdigter beveel om onderdanig te reageer op die begeerte van die koning vir haar, met die erkenning van 'n onderliggende imperatief dat sy haarself ook begeerlik moet maak. Die vermaning word gerig aan die objek (die mooi vrou). Hierdie vermaning staan in diens van begeerte en is ' $n$ aansporing tot skoonheid.

In Spreuke is die vermaning gerig tot die moontlike subjek wat verlei word deur skoonheid. In Spreuke is die mooi vrou die een wat deur haar skoonheid en verleidelike optrede in die man se hart begeerte wek en hom moontlik kan aanmoedig om sy eie en ook haar huwelik te onteer. Spreuke se vermaning tot begeerte, wat in 'n negatiewe lig gestel word, moet binne die konteks van moontlike egbreuk verstaan word. Die vermaning is dus gerig teen begeerte en ontmasker die skoonheid.

\subsection{Konteks}

Die konteks van die twee Skrifgedeeltes bepaal die verskillende verstaansmodi van begeerte en skoonheid. Die sosio-religieuse konteks is belangrik, naamlik die rol van die gesin, die vrou en die huwelik in 'n samelewing wat gedefinieer word in terme van die verbondsverhouding met God. Die huwelik van die koning vind plaas in die milieu van 'n hofhouding waar die onderdanige posisie van die koning se vrou/vrouens 'n gegewe was. Die vrou word in die nuwe situasie ' $n$ verlenging van haar man in die samelewingskonteks. 
In Spreuke word die huwelik bedreig deur die skone en die begeerte. Camp (1985:265) beweer dat in die meer traumatiese post-eksiliese periode, waar die teologie weer eens bevestig moes word, die fokus meer val op die belang van die huis en die gesin as op die koning en die hofhouding.

\subsection{Skoonheid}

In die Psalm 45 staan skoonheid as teken van God se seën en word die skoonheid vir haar (die koningin) en die koning tot wins, deurdat die koning se seën verder gereflekteer word. Ook in haar skoonheid speel hierdie vrou 'n ondergeskikte rol. In Spreuke is skoonheid 'n wins vir die vrou maar nie soseer vir die man nie. Die skoonheid staan buite om die man maar word deur hom erken in die dinamiese ontmoeting. Skoonheid het hier die potensiaal om God se seën vir die gesin en terselfdetyd vir die gemeenskap te vernietig.

\section{Die gebod teen begeerte}

Die tiende gebod 6 het 'n komplekse interpretasiegeskiedenis, wat nou verweef is met die wyse waarop die Dekaloog deur die eeue in die Christelike kerk en die Joodse sinagoge verstaan is. Die Dekaloog is al uit verskeie metodologiese hoeke bestudeer om sodoende ' $n$ verskeidenheid interpretasies te legitimeer.

Veral in die Joodse tradisie staan die Dekaloog sentraal in die wettekorpus as teken van die verbond tussen God en sy volk. Die narratiewe gedeeltes waarbinne die Dekaloog in Eksodus en Deuteronomium ingebed is, vertel van God se verskyning aan die volk (teofanie) en sy direkte oorhandiging van hierdie gebooie aan Moses. Interpreteerders pleit daarom ook, veral vandag, vir 'n wegbeweeg van die verstaan van die Dekaloog as rigiede wette en bevestig die korpus as "tien woorde" wat God tot sy volk binne die verbondsituasie gerig het.

Die identifisering van die eties-ambivalente aard van die begeerte na skoonheid in die Ou Testament (spesifiek Psalm 45:12 en Spreuke 6:25) verskaf sekere teologiese perspektiewe op die verstaan van die tiende gebod in die Dekaloog (Eks. 20:17 en Deut. 5:21).

Die kernvraag in die hantering van die gebod op begeerte is of begeerte bloot dui op 'n gedagte/houding' en of dit noodwendig gepaard gaan met 'n aksie of handeling wat die begeerlike voorwerp vir eie gewin neem. ${ }^{8}$

6 Die indeling van die Dekaloog verskil in die verskillende Christelike tradisies. In die l.utherse en Katolieke tradisies word Eksodus 20:7 verdeel in die negende en tiende gebod.

7 Rofé (1990:57) het gevind dat in al die genres van die Bybelse letterkunde verstaan is as blote begeerte sonder gepaardgaande aksie: wettemateriaal (Deut. 20:12, 14:26), narratief 
Uit 'n juridiese oord verskaf Jackson (1975:210) 'n duidelike uiteensetting vir die moontlike verstaan van die gebod op begeerte. Hy aanvaar die kern as 'n klem op die begeerlike gedagtes ("mental attitude") wat hier ter sprake kom en identifiseer vanuit hierdie probleemarea verskeie gedeeltes in die Ou Testament waar intensie 'n belangrike rol speel (Gen. 6:5; 1 Kon. 8:18; 1 Sam. 16:7). Jackson (1975:212) meen die belangrike is nie die haalbaarheid van regsoptrede teenoor blote intensie nie, maar eerder die erkenning dat God ' $n$ ander standaard handhaaf as die mens. Die gerig/oordeel van God en nie die mens nie is hier te sprake. Dit is vir Jackson (1975:212) die oplossing tot die Dekaloogprobleem. Die Dekaloog is tog nie net etiek nie: "The means of enforcement was the power of God to punish under the terms of the covenant by which Israel accepted the law." Die plig om die gebooie te onderhou was in die Deuteronomistiese tradisie sterk verbind aan die verbondskonsep "dat jy mag lewe". Hierdie kontras tussen lewe en dood na aanleiding van lewenskeuses en optredes is ook duidelik in Spreuke se antitese tussen "vrou wysheid" en die "vreemde/verleidelike vrou".

Jackson (1975:212) kom tot twee gevolgtrekkings: eerstens dat daar geen bewys is dat aanspreekbaarheid op grond van intensie ("liability for mere intention") ooit in die menslike hof in ag geneem is nie, en tweedens figureer die idee wel in die Ou Testament dat die blote intensie tot 'n verkeerde optrede reeds verkeerd is ("merely to intend a wrong was itself wrong"). Hierdie beginsel was verbind aan die reg van God, maar nie die reg van die mens nie. Die reg van God kan as 'n perspektief op die verstaan van die ambivalensie van skoonheid en begeerte gebruik word.

Is hierdie beginsels nie moontlik waar die Dekaloog en die ambivalensie in Spreuke 6 en Psalm 45 bymekaar uitkom nie? Daar waar die gesalfde van God optree binne die huwelik en ander legitieme instellings, daar is begeerte goed, maar daar waar die samelewingsgrense oorskry word (nie net in aksie nie maar ook in gedagtes), word begeerte negatief. Die tiende gebod openbaar God se aanspraak op die mens. So ' $n$ verstaan van die tiende gebod gaan gepaard met 'n sekere verstaan van die samelewing, wat veral voorgestaan is deur die priester- en wysheidsgroepe, wat die tradisies oorgelewer het.

(2 Sam. 23:15), profesie (Amos 5:18; Miga 7:1), poettiese materiaal ( $P$ s. 10:17) en wysheid (Spr. 13:12,23:4, 21:25-26).

8 Phillips (1970) en Nielsen (1968) ondervind probleme na aanleiding van hulle rekonstruksie van die inhoud van die Dekaloog met die blote passiewe verstaan van begeerte en wil die werkwoorde as handelinge interpreteer. 
Wright 9 identifiseer dan ook tereg die sosio-politiese fondament van die verbondsverhouding tussen God en sy volk: "The relationship between Israel and Jahwe was not merely a conceptualized, spiritual entity. It was very deeply rooted in the concrete circumstances of Israel's life - social, economic and political" (Wright, 1979:102). Die shalom van die gemeenskap is in begeerte op die spel. Wright is geneig om die verbondskonsep te verabsoluteer. Dit moet egter in ag geneem word dat die verbond te midde van ryke OuTestamentiese nuanses een van vele metodologiese vertrekpunte kan vorm. Die Dekaloog as norm vir 'n gesonde samelewing maak die verbond wel 'n legitieme uitgangspunt vir die verstaan van die tiende gebod.

Skoonheid kan ook nie in die gebod op begeerte heeltemal buite rekening gelaat word nie. Die dinamiese erkenning van skoonheid kan die begeerte na die naaste se vrou veroorsaak. Daarbenewens staan skoonheid in die teken van God se seën, en moet die besittings en voorspoed van ander, wat as God se seën erken word, gerespekteer word.

Camp (1985:286) verskaf ook insig in die verstaan van die rol van die vrou in die Israelitiese samelewing, veral waar sy 'n kritiese element is in die verstaan van die gemeenskap: "wife defines the "Israeliteness of her house". In die verbod op begeerte na die naaste se vrou wil die Dekaloog juis optree teen denke wat negatief staan teenoor die integrale elemente van die verbondsverhouding.

Die ambivalensie van skoonheid en begeerte is gebind aan die konteks van die gemeenskap en daarom kan die begeerte na die mooi vrou legitiem wees in die hofkonteks (koning as gesalfde), maar nie daar waar 'n vreemde vrou deur haar skoonheid egbreuk aanmoedig nie.

\section{Gevolgtrekking}

Skoonheid, begeerte en die verbod op begeerte is die sleutelmomente in hierdie artikel. Slegs twee gedeeltes in die Ou Testament is geïdentifiseer waar daar eksplisiet van die begeerte van skoonheid (albei 'n mooi vrou) ter sprake is. Weens die grense van die artikel kon nie al die nuanses van die twee begrippe, soos dit ook afsonderlik figureer, ondersoek word nie.

Die dinamiese (skoonheid as gebeure) en die eties-ambivalente aard van skoonheid is geïdentifiseer. Die ambivalensie is ook duidelik in die erkenning dat daar nie 'n enkele verstaan van begeerte is buite die konteks van die Ou-

9 Wright (1989:102) gebruik 'n driehoeksmodel om die Israelitiese samelewing en die verhouding tussen God en mens, soos dit in die Ou Testament se verbondskonsep verstaan word te reflekteer. God, Israel en land vorm die hoeke met die gesin as verbindingselement. 
Testamentiese literatuur nie - 'n konteks wat ook die sosio-religieuse konteks van die tyd weerspieël.

In Psalm 45 is die milieu die viering van 'n monargale huwelik - 'n milieu waarbinne die koning se begeerte vir die skoonheid van sy bruid erken en aangemoedig word en die begeerte sodoende ook legitiem binne die seksuele orde in die monargie is. In Spreuke 6 staan die waarskuwing teen die verleiding van 'n getroude vrou (egbreuk) sentraal. Die vrou van die naaste kan haar skoonheid so gebruik dat ' $n$ man in sy begeerte na hierdie skoonheid sy eie huis en haard, en sodoende die kern van die Israelitiese samelewing, sal versaak.

Die konteks waarbinne skoonheid in die twee Bybelverse gebruik word, bepaal die positiewe of negatiewe aard van die begeerte; begeerte het dus nie ' $n$ eie inherente "boosheid" nie. Begeerte kan seksuele integriteit bevorder of skaad. Hierdie ambivalensie adem 'n groot stuk menslikheid.

Die verantwoordelikheid vir die behoud van integriteit is nie bloot die optrede van die persoon wat die "potensiaal" tot begeerte het nie, maar ook die mooi mens se hantering van haar (in dié geval) skoonheid - 'n skoonheid wat identifiseerbaar is met die seën van God.

Begeerte in die Dekaloog moet in die lig van hierdie ambivalensie verstaan word. As onderdeel van die Dekaloog staan dit in die teken van die shalom en integriteit, wat die verbondsgemeenskap teenoor God en medemens moet kenmerk. Die evaluering van begeerte (en ook vir die mooi mens) kan net gemaak word binne die raamwerk van die Israelitiese selfverstaan van 'n verbondsverhouding, wat vir die tradisie en wysheidversamelaars van groot belang was.

In die ondersoek na skoonheid en begeerte in Psalm 45 en Spreuke 6 is nie die teologiese belang van die "reg of verkeerd" van gesindhede of voorkoms geidentifiseer nie, maar eerder dat die spesifieke teologiese sanksionering van samelewingsinstellings soos dit deur kerngroepe (byvoorbeeld wysheidsleraars) bepaal is, die konteks en beoordeling van skoonheid en begeerte in die $\mathrm{Ou}$ Testament gevorm het. 


\section{Bibliografie}

AUGUSTIN, M. 1983. Der Schone Mensch im Alten Testament und im hellenistischen Judentum. Frankfurt am Main : Peter Lang.

CAMP, C.V. 1985. Wisdom and the feminine in the Book of Proverbs. Sheffield : JSOT Press.

JACKSON, B.S. 1975. Essays in Jewish and comparative legal history. Leiden : Brill.

KRAUS, H.J. 1986. The theology of the Psalms. Minneapolis : Fortress Press.

MAYER, G. 1973. אור. (In Theologische Worterbuch zum Alten Testament. Band 1. Stuttgart : Kohlhammer. p. 145-148.)

MAYS, J.L. 1994. The Book of Psalms. (Volume 1.) New Century Bible. Louisville : John Knox Press.

McCANE, W. 1970. Proverbs. (A new approach.) The Old Testament Library. London : SCM.

MICKLER, J.J. 1983. A Scriptural, historical and theological study of the idea of concupiscence as it relates to representative theories of original and actual $\sin$ in contemporary Catholic ethical systems. Fordham University. (M.A. Dissertation.)

NIELSEN, E. 1968. The Ten Commandments in new perspective. A traditio-historical approach. London : SCM.

PATTERSON, R.D. A multiplex approach to Psalm 45. Grace Theological Journal, 6(1):2948.

PHILLIPS, A. 1970. Ancient Israel's criminal law. A new approach to the Decalogue. Oxford : Blackwell.

REINES, C.W. 1975. Beauty in the Bible and the Talmud. Judaism, 24:100-107.

ROFÉ, A. 1990. The tenth commandment in the light of the four Deuteronomic laws. (In Segal, B. The Ten Commandments in history and tradition. Hebrew University Jerusalem : Magness Press. p. 45-65.)

VON RAD, G. 1961. Theologie des Alten Testaments. Band 1. München : Kaiser Verlag.

WALLIS, G. 1973. . Tָָ. (In Theologische Wörterbuch um Alten Testament. Band II. Stuttgart : Kohlhammer. p. 1021-1031.)

WESTERMANN, C. 1977. Das Schöne im Alten Testament. (In Donner, H. et al. Festschrift W. Zimmerli. Göttingen : Vandenhoeck \& Ruprecht. p. 479-497.)

WOLFF, H.W. 1974. Anthropology of the Old Testament. Philadelphia : Fortress Press.

WRIGHT, C.J.H. 1979. The Israelite household and the Decalogue: The social background and significance of some commandments. Tyndale Bulletin, 30:101-124. 